\title{
Serial Distortion Patterns of the Vertebral Column Due to Schoolbag Carriage: A Case Report
}

Paul Y, Moraba LM*, Kurten M, Barnard M, Ellapen TJ

Department of Sport Rehabilitation and Dental Sciences, Tshwane University of Technology, South Africa

DOI: $10.36348 /$ jaep.2020.v04i10.005

| Received: 14.09 .2020 | Accepted: 21.09.2020 | Published: 30.10.2020

*Corresponding author: Lehlogononolo Moraba

\section{Abstract}

The habitual carriage of heavy school backpacks by scholars has been associated with a clumsy forward leaning compensatory posture that has become a concern to both parents and medical practitioners. This report documents the change in sagittal plane posture by quantifying the variation in craniovertebral (CVA) and standing pelvic angles (SPA), as well as vertex and acrominale heights during the loaded (carrying of the school backpack) versus the unloaded (not carrying the school backpack) phases. The school backpack weighed $6.8 \mathrm{~kg}(20.0 \%$ of the scholar's body mass). The scholar carried the straps of the backpack on both shoulders respectively. There was a significant difference in vertex and acrominale heights during loaded versus unloaded phases $(\mathrm{p}=0.02)$. A positive association was found between the anterior pelvic tilt and diminished vertex height $(\mathrm{r}=0.99)$ indicating that heavy backpack carriage diminishes the child's vertex height by anteriorly rotating the pelvis. Furthermore, there was a positive association with the change in CVA and SPA ( $\mathrm{r}=0.89$ ) suggesting that carrying heavy backpacks produces a complimentary diminished CVA with an increased SPA in order to accommodate the increased load on the vertebral column.

Keywords: cervical, lumbar lordosis, school backpack, serial distortion, vertebrae.

Copyright (C) 2020 The Author(s): This is an open-access article distributed under the terms of the Creative Commons Attribution 4.0 International License (CC BY-NC 4.0) which permits unrestricted use, distribution, and reproduction in any medium for non-commercial use provided the original author and source are credited.

\section{INTRODUCTION}

The awkward forward leaning posture of scholars carrying heavy schoolbags has become a common and worrisome concern of many parents. The general rule of thumb when carrying backpacks is that mass should not exceed $10 \%$ of the person's body mass [1]. Unfortunately, many studies have documented scholars carrying school backpacks exceeding this value, resulting in deviated posture in both the sagittal and frontal planes, accompanied by neuromusculoskeletal pain [2]. While numerous biomechanical investigations have reported incidences of excessive cervical lordotic [3] and lumbar lordotic postures [4] due to heavy school backpack carriage, no empirical study has reported on the incidence of cervico- kypholordotic posture due to the habitual carrying of heavy school backpacks and described the pathomechanics responsible for this misaligned posture. Hammill et al. [5] explained the serial distortion of the lumbopelvic-hip complex caused by heavy school backpack carriage: heavy school backpacks cause the pelvic girdle to rotate anteriorly, subsequently generating a serial distortion in the alignment of the upward lumbar vertebrae causing a more lordotic curve [5]. This, in turn, has been associated with lower back pain [5]. It has been anecdotally postulated that the habitual carrying of heavy school backpacks produces a cervico-kypholordotic posture which is a serial distortion of the anterior-posterior curves of the cervical, thoracic and lumbar vertebrae. This serial distortion affects the kinematic alignment of the sagittal plane producing a reduced craniovertebral angle (CVA), an excessive thoracic kyphosis cobb angle and excessive lumbar lordosis. This unique case report quantifies the incidence of cervico-kypholordotic posture due to heavy school backpack carriage.

\section{METHODS}

Participants: A 12 year old male scholar (grade six) presented a misaligned sagittal plane posture accompanied with musculoskeletal pain in the shoulders, cervical and lumbar regions when carrying his school backpack. The pubescent's parent initially requested a consultation for posture analysis, thereafter seeking biokinetic rehabilitation. Biokinetics is a rehabilitative profession that prescribes exercises and physical activities to rehabilitate various pathologies [6]. Both pubescent and parent provided child ascent and parental informed consent for this report. 
Procedure: Postural analyses in sagittal and frontal planes were conducted as per the Prentice postural analysis protocol [7]. Initially the scholar's posture, kinathropometrical measures (body mass, vertex and acrominale heights), school backpack, and biomechanical angles [craniovertebral (CVA) and standing pelvic angles (SPA)] were measured in the unloaded phase (not carrying backpack) as well as during the loaded phase (carrying the backpack). The kinathropometrical measures were recorded as per the International Standards for Kinanthropometric Assessments [8]. The biokineticist adopted the Hande protocol [9] in order to measure the pubescent's CVA, and Starkey's protocol [10] in order to measure SPA. The diminished CVA indicated altered neck on body angle, suggesting cervical postural syndrome. The increased standing pelvic angle indicated an anterior pelvic rotation (short-arc pelvic-on-femur flexion).

\section{DATA ANALYSES}

Included inferential statistical tests in order to measure the association between the change in vertex height and anterior pelvic rotation, as well as the relationship between the change in CVA and anterior pelvic rotation (suggestive of the serial distortion of the vertebral column due to school backpack carriage) were undertaken. Furthermore, a t-test was conducted in order to determine whether the change in CVA and SPA that occurred was significant when the pubescent carried the backpack as compared to when he did not $(\mathrm{p}<0.05)$.

\section{RESULTS}

Table 1 details the measured variables of the unloaded as compared to the loaded phase. The school backpack weighed $6.8 \mathrm{~kg}$ equating to $20.0 \%$ of the scholar's body mass. The scholar carried the straps of the backpack on both shoulders. A significant difference in vertex and acrominale heights during the loaded as compared to the unloaded phases was found (Table 2). A Pearson correlation test was conducted so as to determine the association between anterior pelvic tilt and diminished vertex height $(r=0.99)$ and a positive correlation between the changes in CVA and SPA was determined $(r=0.89)$.

Table-1: Postural changes during unloaded versus loaded phases
\begin{tabular}{|l|l|l|}
\hline Variables & Unloaded phase & Loaded phase \\
\hline Vertex height $(\mathrm{cm})$ & 139.0 & 137.8 \\
\hline Acrominale height $(\mathrm{cm})$ & 113.5 & 112.5 \\
\hline Body mass $(\mathrm{kg})$ & 33.9 & 40.8 \\
\hline CVA $\left(^{\circ}\right)$ & 46 & 40 \\
\hline PSA $\left({ }^{\circ}\right)$ & 19 & 30 \\
\hline
\end{tabular}

Table-2: Comparative review of change in kinathropometrical height differences during loaded versus loaded phases

\begin{tabular}{|l|l|l|}
\hline Heights & Unloaded phase & Loaded phase \\
\hline Vertex $(\mathrm{cm})$ & 139.0 & 137.8 \\
\hline Acrominale $(\mathrm{cm})$ & 113.5 & 112.5 \\
\hline Mean $( \pm \mathrm{SD})$ & $126.5( \pm 18.03)$ & $125.15( \pm 17.88)$ \\
\hline p-value & 0.02 & \\
\hline
\end{tabular}

\section{DISCUSSION}

Carrying heavy school backpacks alters CVA [9] and kypholordotic postures [4], which concurs with the findings of this case report. In addition, carrying a school backpack weighing greater than $10 \%$ of the incumbent body mass has been reported to produce vertebral musculoskeletal pain [11] which supports the findings of this case study. The unique finding of this report lies in the association between anterior pelvic tilt and diminished vertex height. Vertex height is the measure of an individual's total height from the ground to the most cranially superior point [8]. The authors propose that the reduction in vertex height is due to the anterior rotation of pelvis producing upward serial distortion of the vertebral column closed-kinetic-chain system. An anteriorly rotated pelvis produces hyperextension of the lumbar vertebrae which in turn produces excessive lordosis [5]. By altering the anterior curve of lumbar vertebrae, the superior lying vertebrae in the thoracic also become more posteriorly aligned, producing excessive kyphosis (kypholordotic posture) [12]. However, the anterior-posterior curves extend from the lumbar vertebrae through the thoracic and finish in the cervical vertebrae. The authors postulate that the body also attenuates the cervical vertebrae anterior curve, thereby diminishing its CVA and creating a cervico-kypholordotic posture.

\section{CONCLUSION}

The above novel findings indicate that children carrying heavy school backpacks diminish their CVA while simultaneously increasing their SPA in an attempt to accommodate the increased load on the vertebral column in addition to standing upright. Carrying heavy school backpacks decreases vertex height, which is due to an anterior rotation of the pelvis. These novel findings must be considered when physiotherapists, occupational therapists and biokineticists prescribe 
rehabilitative lumbopelvic stabilization exercises. Further empirical investigations are needed to confirm these findings.

\section{REFERENCES}

1. Voll, H., \& Klimt, F. (1977). Strain in children caused by schoolbags. Offentliche Gesundheitswesen, 39, 369-378.

2. Pant, K., Kaur, H., \& Sidhu, M. (2016). Ergonomics evaluation of various risk factors associated with carrying schoolbags. International Journal of Scientific Research, 5(2), 16-18.

3. Hundekari, J., Chilwant, K., Vedpathak, S., \& Wadee, S. (2013). Does alteration in backpack load affects posture in school children? IORS Journal of dental and Medical Science, 7(4), 71-75.

4. Smith, A., O’Sullivan, P., \& Straker, L. (2008). Classification of sagittal thoraco-lumbo-pelvic alignment of the adolescent spine in standing and its relationship to low back pain. Spine, 33(19), 2101-2107.

5. Hammill, H.V., Ellapen, T.J., \& Swanepoel, M. (2017). The health impact of schoolbag carriage: A systematic review (2007-2016). African Journal for Physical Activity and Health Sciences, 23(2), $245-$ 260.
6. Ellapen, T.J., \& Swanepoel, M. (2017). The Evolution of the Profession of Biokinetics. South African Journal of Research in Sport Physical Education Recreation, 39(1), 41-50.

7. Prentice, W.E. (2011). Rehabilitation Techniques for Sports Medicine and Athletic Training ( $5^{\text {th }}$ ed.). Champaign, IL: Human Kinetics.

8. Stewart, A., Marfell-Jones, M., Olds, T., \& De Ridder, H. (2011). International standards for anthropometric assessment. Lower Hutt: New Zealand.

9. Hande, D.N., Shinde, N., Khatri, S.M., \& Dangat, P. (2012). The effect of backpack on cervical and shoulder posture in male students of Loni. International Journal of Health Science \& Research, 2(3), 72-79.

10. Starkey, R. (2002). Evaluation of Orthopeadic and Athletic injuries ( $2^{\text {nd }}$ Ed.), Philadelphia, United States of America: FA Davis Company

11. Walikca-Cuprys, K., Shalska-Izdebska, R., Rachwal, M. \& Truszcynska, A. (2015). Influence of weight of a school backpack on spinal curvature in the sagittal plane of seven year old children. BioMedical Research International, http://dx.doi.org/10.1155/2015/817913

12. Mansfield, P.J., \& Neumann, D.A. (2009). Essentials of kinesiology for the physical therapist assistant. St. Louis, Missouri: Mosby, Inc. 